\title{
Os adolescentes infratores do Rio de Janeiro e as instituições que os "ressocializam". A perpetuação do descaso
}

\author{
Teenage law offenders in Rio de Janeiro \\ and institutions that "rehabilitate" them: \\ the perpetuation of negligence
}

Maruza B. Oliveira 1

Simone G. Assis 2

\footnotetext{
1 Primeira Vara da Infância e da Juventude.

Praça Onze de Junho 403,

Cidade Nova, RJ

20210-010, Brasil.

2 Centro Latino Americano

de Estudos de Violência

e Saúde, Escola Nacional

de Saúde Pública,

Fundação Oswaldo Cruz.

Av. Brasil 4036, sala 702,

Manguinhos, Rio de Janeiro,

RJ, 21040-361, Brasil.
}

\begin{abstract}
This article presents data from juvenile delinquents in the Rio de Janeiro Minors Court. It is an exploratory study with qualitative and quantitative approaches, conducted in 1994 in three schools (Padre Severino Institute, João Luiz Alves School, and Santos Dumont School) in Greater Metropolitan Rio de Janeiro and responsible for the legal custody of juvenile delinquents. Social and demographic aspects of the adolescents and families are shown, and the daily routines of employees, adolescents, and researchers are reported. This paper stresses the damaging effects on the lives of these youngsters by their families, society, and judiciary and legal custody institutions. It also suggests approaches and positive ways of reorienting the issue.
\end{abstract}

Key words Youth; Repeat Offenses; Violence

Resumo Este artigo apresenta dados sobre adolescentes envolvidos em processos na Justiça da Infância e Juventude. Trata-se de estudo exploratório composto por uma abordagem qualitativa e quantitativa, realizado no ano de 1994 em três escolas (Instituto Padre Severino, Escola João Luiz Alves e Educandário Santos Dumont) situadas no Município do Rio de Janeiro, responsáveis pela custódia judicial de adolescentes infratores. São apresentados dados do perfil sócio-demográfico dos adolescentes e suas famílias e relatado o cotidiano vivenciado por funcionários, adolescentes e pesquisadores. O trabalho busca demonstrar os efeitos danosos da vida imposta a esses jovens, seja pela família, sociedade, judiciário e instituições de custódia e sugere propostas de abordagens e encaminhamentos para a problemática investigada.

Palavras-chave Juventude; Reincidência Infracional; Violência 


\section{Introdução}

A violência praticada por crianças e adolescentes é, hoje, um problema para a sociedade brasileira, acompanhando uma tendência mundial de incremento deste fenômeno (Mones, 1991; Shoemaker, 1996). Estas crianças e jovens, cada vez mais considerados perigosos pela sociedade, são freqüentemente internados ou detidos em instituições correcionais. Esta medida de restrição de liberdade tem sido utilizada para o enfrentamento desta questão, tanto por países desenvolvidos como por aqueles em desenvolvimento (Hawkins, 1996).

Este artigo apresenta dados coletados no ano de 1994, sobre os jovens infratores que deram entrada nos Juizados da Infância e Juventude do Estado do Rio de Janeiro e que foram encaminhados para as três únicas instituições existentes no Estado. Também analisa as impossibilidades e limitações do sistema de internamento de infratores no país e, especialmente, no Rio de Janeiro, desde seu início até o momento atual.

\section{A delinqüência juvenil no Brasil}

Os atos violentos praticados por crianças e adolescentes vêm sendo descritos no país desde o século XIX. Em 1830, o Código Criminal do Império recomendava internação em "casa de correção" a menores de 14 anos que tivessem cometido - com discernimento - atos indesejados pela sociedade (Rizzini, 1993). Publicações e periódicos do fim deste século apontavam as ruas das grandes cidades brasileiras como espaços povoados por crianças pobres, "vadias", que incorriam em delitos como furtos e roubos e eram presos em cadeias públicas como criminosos comuns (Londoño, 1991).

Há registro de que do ano de 1894 para 1895 os crimes cometidos por crianças e adolescentes na faixa dos 9 aos 20 anos de idade, em São Paulo, passaram de 59 para 97. Todos foram presos em cárceres públicos, mesmo existindo lei que indicava a criação de instituições próprias a menores (Londoño, 1991).

Nos primeiros anos do século XX surgiram projetos legislativos defendendo o direito do menor e, em 1913, foi criada a primeira instituição para atender o infrator: o Instituto Sete de Setembro, que recebia tanto infratores quanto desvalidos.

No ano de 1917, foi apresentada ao Senado a primeira lei que considerou como "não criminosos" os adolescentes entre 12 e 17 anos. Em 1927, começou a vigorar no Brasil o Código de Menores, sendo o primeiro país da América Latina a implantar medidas específicas para esta faixa etária (FUNABEM, 1984). Esta lei garantia que o menor de 14 anos não seria submetido a processo penal de natureza alguma (o que acabava com a questão do discernimento que vinha desde o Império) e que o adolescente entre 14 e 18 se submeteria a processo especial (Faleiros, 1995).

O desconforto provocado na sociedade por esta situação cresceu gradativamente, a ponto de ocupar os meios de imprensa e literários. Exemplo disto pode ser verificado em livro de ficção, publicado em 1937 (Amado, 1984:11): “o que se faz necessário é uma urgente providência da polícia e do Juizado de Menores no sentido da extinção desse bando e para que recolham esses precoces criminosos, que já não deixam a cidade dormir em paz o seu sono tão merecido, aos institutos de reforma de crianças ou às prisões". Este bando é citado no texto como as "crianças ladronas” para as quais se solicitavam medidas de repressão urbana.

Em 1941 foi criado um sistema nacional chamado Serviço de Assistência ao Menor (SAM) em substituição ao Instituto Sete de Setembro, mantendo o objetivo de assistir desvalidos e infratores. Entretanto, com o passar dos anos, sua atuação marcou-se por uma estrutura administrativa burocrática, pouco eficiente, sem autonomia e flexibilidade (FUNABEM, 1984) e por uma política repressora e sinônimo de horror. Suas instalações físicas eram inadequadas: os menores ficavam amontoados em situações promíscuas, possuía técnicos despreparados, dirigentes omissos e eram freqüentes os espancamentos sofridos pelas crianças. Alguns juízes passaram a condenar o SAM como fábrica de delinqüentes, escolas do crime, lugares inadequados, sistema desumano, ineficaz e perverso (Faleiros, 1995).

Buscando escapar desta situação, criou-se no ano de 1964, a Fundação Nacional de Bem Estar do Menor (FUNABEM) e seus órgãos executores (Fundação Estadual de Bem Estar do Menor, etc.), em substituição ao SAM. Todo a atuação desenvolvida por estas instituições eram diretamente dependentes da esfera federal. Os ideais iniciais da FUNABEM eram bastante ambiciosos: pesquisar métodos, testar soluções, estudar técnicas que conduzissem à elaboração científica dos princípios que deveriam presidir toda a ação que visasse à reintegração do menor à família e à comunidade. Sua meta era a abordagem preventiva e sócio-terapêutica.

A tecnocracia e o autoritarismo que caracterizaram a FUNABEM, aliada aos interesses dos juizes de menores fizeram com que fosse 
promulgada, em 1979, o novo Código de Menores que cria o menor "em situação irregular”, desde o abandonado ao autor de infração penal.

Novamente o quadro se repetiu e a FUNABEM necessitou ser extinta pelos mesmos motivos que o SAM o fora: condições físicas insalubres e inadequadas e maus-tratos sofridos pelos menores internos nas unidades oficiais, que iam desde a violência física, estupros, uso de psicotrópicos e toda sorte de ações que visavam fazer o menor perder a sua individualidade e sua capacidade de pensar (Luppi, 1987; Altoé, 1990).

Em 1990, promulgou-se o Estatuto da Criança e do Adolescente - ECA (MS, 1991), fruto da ratificação da Declaração Universal dos Direitos da Criança e do Adolescente da Organização das Nações Unidas (ONU), que passou a considerar a população infanto-juvenil como sujeito de direito e merecedora de cuidados especiais e proteção prioritária. Esta lei revogou o Código de Menores de 1979.

Este Estatuto, considera que são penalmente inimputáveis os menores de dezoito anos que cometem crime ou contravenção penal. A estes jovens não podem ser perpetradas penas, e sim medidas sócio-educativas de advertência, obrigação de reparar o dano, prestação de serviços à comunidade, liberdade assistida, inserção em regime de semi-liberdade, internação em estabelecimento educacional, além de outras medidas que visem ao acompanhamento do infrator na família, escola, comunidade, serviços de saúde etc. A medida de internação é aquela que coloca o infrator sob custódia do Estado, privando-o de liberdade total ou parcial. Esta medida somente pode ser aplicada pelo juiz em caso de infração cometida por meio de grave ameaça ou violência à pessoa e no caso de reincidência de ato infracional grave. Não há previsão de tempo para a internação, contudo, a permanência do jovem nesse estabelecimento não pode ultrapassar o prazo de três anos, devendo ser a mesma avaliada a cada semestre. A libertação será compulsória aos vinte e um anos de idade.

Neste mesmo ano de 1990, crucial para a elaboração e aprovação do ECA, a FUNABEM foi extinta e criada a Fundação Centro Brasileiro da Infância e Adolescência (FCBIA), com a missão de coordenar, normatizar e formular políticas (assessorando e repassando verbas), já que a execução seria feita por estados e municípios, seguindo a estratégia de descentralização prevista no ECA (Faleiros, 1995).

No Rio de Janeiro, em 1993, a Secretaria de Justiça celebrou convênio com a FCBIA. Para assumir as tarefas federais e para efetivar as mudanças concretas no sistema foi criado o Departamento Geral de Ação Sócio-Educativa (DEGASE), no ano de 1993. O ano de 1994, período em que foi realizada esta pesquisa, foi marcado historicamente pelo estabelecimento concreto dessas mudanças no Estado do Rio de Janeiro; o que antes era responsabilidade federal, tornou-se inscrito na responsabilidade Estadual. Como conseqüência dessa descentralização em todo o país, a FCBIA foi extinta em 1995.

\section{As instituições de internação para infratores no Estado do Rio de Janeiro}

Em 1994 existiam três escolas destinadas aos infratores no Rio de Janeiro: duas delas destinadas a jovens do sexo masculino, estadualizadas neste ano e uma voltada para meninas infratoras, já sob a tutela estadual.

O Instituto Padre Severino (IPS) foi criado em 1954 e hoje caracteriza-se como unidade de atendimento direto ao adolescente do sexo masculino a quem se atribui prática de ato infracional. Recebe adolescentes encaminhados pela Delegacia de Polícia da Criança e do Adolescente (DPCA) e pelos Juizados da Infância e Juventude (JIJ). Serve como instituição de triagem, até que os adolescentes recebam o resultado da audiência com o juiz, num prazo máximo (segundo a lei) de 45 dias. Era capaz de absorver uma demanda de até 150 adolescentes; no entanto, possuía habitualmente 200 ou mais internos, sujeitos a precárias condições de vida.

A Escola João Luiz Alves (EJLA) foi inaugurada em 1928. Atualmente, sua competência se restringe a executar o cumprimento da medida judicial sócio-educativa de internação, para adolescentes a que se atribuiu prática de ato infracional, encaminhados pelos Juizados da Infância e Juventude. Visa à permanência e custódia judicial. O espaço físico era privilegiado até que, em 1994, houve uma grande destruição da instituição após rebelião dos internos. Funcionava também com excesso de internos em relação à capacidade física (suportava até 128 infratores).

O Educandário Santos Dumont (ESD) atende a adolescentes do sexo feminino na faixa de 12 a 18 anos, oriundas de todas as localidades do Rio de Janeiro, encaminhadas pelos Juizados da Infância e Juventude, em virtude da atribuição de atos infracionais. Na ocasião em que foi implantada a FUNABEM, o atendimento à jovem estava sob a responsabilidade do Estado do Rio de Janeiro. O Educandário Santos Du- 
mont era também chamado de Centro de Recepção e Triagem - CRT1. Estava vinculado a Diretoria de Promoção Social da Fundação Estadual do Menor (FEEM), órgão da Secretaria de Estado de Educação e Cultura, responsável por atender adolescentes em situação irregular. A faixa etária atendida era de 14 a 18 anos, do sexo feminino, em regime de internação em sistema fechado, com características de triagem e permanência. Nesta época, o Educandário tinha capacidade para receber 150 adolescentes, procedentes do Juizado de Menores, Delegacia de Segurança e Proteção ao Menor, Delegacias Distritais e Fundação Estadual de Educação ao Menor.

Em 1980, o Educandário atendia simultaneamente as demandas da Primeira Vara da Infância e Juventude, que encaminhava jovens carentes sem referência familiar, e da Segunda Vara, responsável por adolescentes em situação irregular. Essa concomitância no atendimento acarretava algumas conseqüências, dentre as quais a mais notável era a divisão da clientela no interior da instituição, o que implicava uma separação do espaço, tornada visível por um portão gradeado que separava o pátio e o dormitório das jovens. Apesar desta separação, todas conviviam afinal num mesmo espaço. As dependências comuns eram o refeitório, as salas de aula, as salas de profissionalização, a piscina e o pátio. Essa situação apenas foi modificada em 1994, quando o Educandário passou a se dedicar exclusivamente ao atendimento às jovens infratoras, numa unidade com capacidade para cerca de 40 internas.

\section{Material e métodos}

Este trabalho apresenta parte dos resultados da pesquisa "As Implicações Psíquicas Presentes no Ato Infracional de Repetição", realizada com o apoio do Juizado da Infância e Juventude (Bastos, 1994a, 1994b, 1995). Os materiais e métodos apresentados a seguir são um recorte da metodologia empregada na pesquisa como um todo. Os resultados apresentados neste texto foram originados de:

- um censo com todos os adolescentes institucionalizados, em dias específicos nas três instituições investigadas, com objetivo de construir um perfil sócio-demográfico dos adolescentes e de suas famílias. Cinco por cento dos adolescentes presentes na instituição não demonstraram disponibilidade para responder ao questionário preparado pela equipe de pesquisa. Uma vez que a enquete buscou preservar a participação voluntária, os adolescentes não precisaram justificar a recusa de participação e este movimento foi prontamente aceito pela equipe como um direito do jovem;

- 11 entrevistas em profundidade, baseadas em roteiro semi-estruturado, foram realizadas com funcionários que ocupavam lugares-chave nas instituições, como a de direção, o setor de educação e os inspetores; pesquisa documental nas instituições; e diário de campo dos pesquisadores, visando contextualizar o cotidiano institucional vivenciado por funcionários, adolescentes e pesquisadores no ano de 1994.

A equipe de pesquisa esteve presente nas instituições de agosto de 1993 a junho de 1995.

Todos os percentuais apresentados no texto foram calculados retirando-se as informações incompletas ou ausentes.

\section{Resultados \\ O perfil da clientela}

Durante o censo das três escolas foram entrevistados 537 internos presentes nas instituições em dias distintos. Como se pode verificar na Tabela 1, apenas no Instituto Padre Severino (IPS) houve um número maior de recusas.

Como se pode perceber, o IPS é a instituição com maior número de internos (37\%), seguido pela Escola João Luis Alves - EJLA (35\%) e da Escola Santos Dumont - ESD (28\%).

Tabela 1

Distribuição da população segundo instituição investigada.

\begin{tabular}{lrrrrrrrr}
\hline População & IPS & $\%$ & EJLA & $\%$ & ESD & $\%$ & Total & $\%$ \\
\hline Participante & 195 & 88 & 190 & 98 & 152 & 100 & 537 & 95 \\
Não participante & 28 & 12 & 3 & 2 & - & - & 31 & 5 \\
Total & 223 & 100 & 193 & 100 & 152 & 100 & 568 & 100 \\
\hline
\end{tabular}


Número de entradas na instituição segundo a população entrevistada.

\begin{tabular}{|c|c|c|c|c|c|c|c|c|}
\hline \multirow[t]{2}{*}{ Entradas } & \multicolumn{2}{|c|}{ IPS } & \multicolumn{2}{|c|}{ EJLA } & \multicolumn{2}{|c|}{ ESD } & \multicolumn{2}{|c|}{ Total } \\
\hline & $\mathrm{n}$ & $\%$ & $\mathrm{n}$ & $\%$ & $\mathrm{n}$ & $\%$ & $\mathrm{n}$ & $\%$ \\
\hline 1 & 115 & 59,1 & 134 & 70,5 & 110 & 72,4 & 359 & 66,8 \\
\hline 2 & 35 & 17,9 & 31 & 16,3 & 11 & 7,2 & 77 & 14,3 \\
\hline 3 & 13 & 6,7 & 11 & 5,8 & 11 & 7,2 & 35 & 6,5 \\
\hline 4 & 11 & 5,6 & 7 & 3,7 & 7 & 4,6 & 25 & 4,7 \\
\hline $5-9$ & 18 & 9,2 & 4 & 2,1 & 6 & 4,0 & 28 & 5,2 \\
\hline $10 \mathrm{ou}+$ & 3 & 1,5 & 0 & 0 & 7 & 4,6 & 10 & 1,9 \\
\hline Sem informação & - & - & 3 & 1,6 & - & - & 3 & 0,6 \\
\hline Total & 195 & 100 & 190 & 100 & 152 & 100 & 537 & 100 \\
\hline
\end{tabular}

No que se refere à passagem do adolescente pelo circuito judicial, percebe-se que cerca de $67 \%$ dos internos revelaram-se primários, observando-se, portanto, que em cada três internos, um era reincidente. O IPS apresentou o maior percentual de reincidentes $(40,9 \%)$.

Dos 537 adolescentes recenseados nessas instituições, apenas 471 já tinham suas medidas determinadas pelo juiz. Logo, 66 deles encontravam-se acautelados, aguardando resolução para sua situação. Os resultados apresentados no correr deste texto referem-se ao total de entrevistados (537), exceto para a Tabela 3 e Figura 1, que dizem respeito aos 471 adolescentes para os quais havia medida sócio-educativa determinada no momento da entrevista.

Dentre aqueles 471 já com medida determinada pelo juiz, pode-se visualizar, na Tabela 3 , que as infrações mais comumente cometidas são aquelas contra o patrimônio - 62,6\% (violação de domicílio, furtos, roubos, danos à propriedade, estelionato, receptação), seguidas pela prevenção ou repressão ao tráfico ou uso de substâncias entorpecentes $(10,9 \%)$. Outras infrações menos freqüentes são os crimes contra a vida e contra a pessoa $-5,7 \%$ (lesão corporal, indução ou auxílio ao suicídio, homicídio), os contra a liberdade sexual $-0,4 \%$ (estupro) e contra a paz pública $-0,9 \%$ (formação de quadrilha ou bando, desacato à autoridade, facilitação da fuga de presos).

A distribuição do ato infracional é distinta segundo a instituição investigada, como se pode verificar na Figura 1.

Como se pode perceber, os crimes contra furto e roubo (patrimônio) são os mais comuns em ambos os sexos e os crimes contra a vida são muito pouco praticados pelas infratoras da ESD, que também são mais freqüente-
Tabela 3

Tipos de infrações cometidas pelos entrevistados.*

\begin{tabular}{lrc}
\hline Ato infracional & n & $\%$ \\
\hline Tráfico de drogas & 38 & 8,1 \\
Tráfico em grupo & 8 & 1,7 \\
Uso de drogas & 5 & 1,1 \\
Homicídio & 20 & 4,2 \\
Auxílio ao suicídio & 1 & 0,2 \\
Lesão corporal & 6 & 1,3 \\
Violação de domicílio & 1 & 0,2 \\
Furto & 159 & 33,8 \\
Roubo & 125 & 26,5 \\
Dano a propriedade & 4 & 0,8 \\
Estelionato & 1 & 0,2 \\
Receptação & 5 & 1,1 \\
Estupro & 2 & 0,4 \\
Quadrilha ou bando & 2 & 0,4 \\
Desacato & 1 & 0,2 \\
Facilitar a fuga & 1 & 0,2 \\
Não especificado** & 92 & 19,5 \\
Total & 471 & 100
\end{tabular}

* Nos casos em que o adolescente apresentou mais de um ato infracional, optou-se pelo artigo que mais influenciou no agravamento da ação principal.

** Composto essencialmente por adolescentes vindos de comarcas do interior cujos prontuários não esclareciam a natureza da infração. 
Figura 1

Distribuição dos adolescentes segundo ato infracional cometido. IPS, EJLA, ESD, 1994
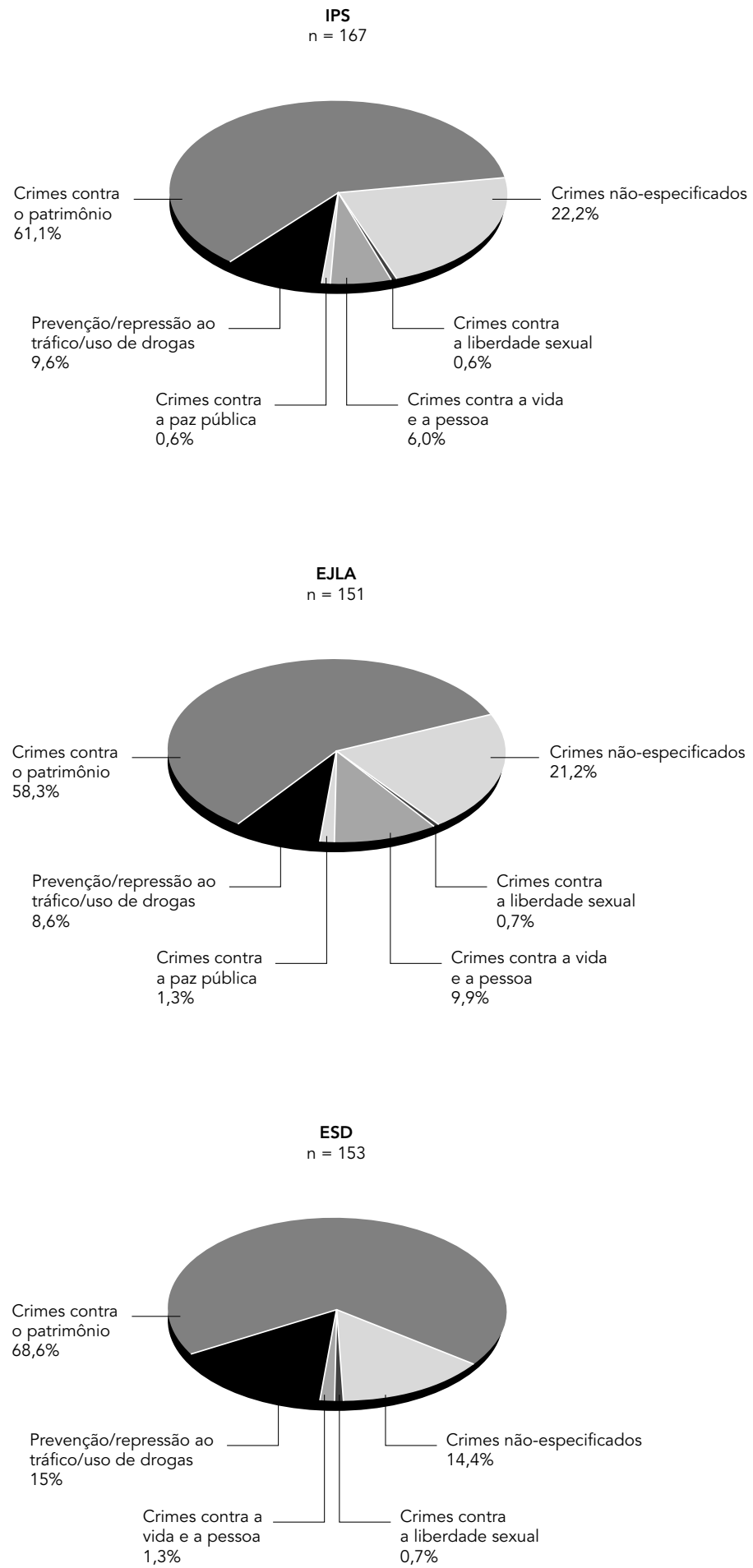

mente detidas por crimes ligados ao consumo ou tráfico de drogas que os internos do IPS e EJLA.

A cidade do Rio de Janeiro foi a principal localização onde estas infrações foram cometidas - $54,6 \%$, seguida pela região de Niterói e São Gonçalo, com $21,4 \%$ dos casos e em terceiro lugar, a Baixada Fluminense com 14,4\%. Estas três áreas compõem a região metropolitana do Rio de Janeiro. No interior, a Região Serrana foi a mais expressiva no que se referiu a atos infracionais cometidos por adolescentes, com $5,3 \%$ do total.

Em relação aos 20 infratores que cometeram homicídios, percebe-se que apenas 4 deles (20\%) cometeram o crime na capital, enquanto 8 o fizeram na Baixada Fluminense $(40 \%)$. No que se refere aos 284 crimes de roubo e furto, $63 \%$ deles ocorreram na capital, enquanto 12,3\% foram cometidos em Niterói e somente $10,6 \%$ na Baixada Fluminense. A mesma realidade ocorre no que se refere aos 51 casos de tráfico/uso de drogas: $58 \%$ ocorreram na capital, 23\% em Niterói e 15\% na Baixada. As outras regiões do Estado são responsáveis pelos casos restantes. Torna-se fácil constatar a diferente incidência com que os crimes se distribuem: na capital são mais comuns os crimes contra o patrimônio e relacionados às drogas, enquanto em áreas mais carentes com a Baixada Fluminense predominam aqueles mais graves, contra a vida humana.

No que se refere à faixa etária dos entrevistados, pode-se verificar na Figura 2, que o contingente mais expressivo de internos encontrase com 16 e 18 anos, mas é também significativo o número de jovens com 14 e 15 anos.

É importante ressaltar que existem diferenças entre os adolescentes das três escolas: as meninas internadas são mais novas que os rapazes e os infratores do IPS são mais velhos que os da EJLA. Merece também destaque o fato de que há um elevado percentual de internos com 18 anos ou mais $(8,2 \%)$. Estes internos maiores são preocupação constante dos funcionários responsáveis pela segurança.

Em relação à naturalidade dos adolescentes internados, tem-se que $92,6 \%$ são nascidos e residem no próprio Estado do Rio de Janeiro, sendo que $6,5 \%$ dos entrevistados declararam que são oriundos de outros Estados. O local de moradia referido por $43,4 \%$ dos internos é a cidade do Rio de Janeiro, especialmente os subúrbios da Leopoldina e Zona Norte. Em seguida, vêm os adolescentes moradores da Baixada $-22,4 \%$ e de Niterói - 19,9\%.

A existência de documentação oficial dos adolescentes também foi investigada nesta pes- 
quisa, por ser representativa da integração social e do grau de cidadania alcançado. A identidade social esteve ausente da vida de $9 \%$ dos internos que sequer possuíam certidão de nascimento e por conseqüência nenhum outro documento. Apenas 19\% tinham carteira de identidade e $29 \%$ carteira profissional. Em relação ao sexo feminino, o percentual de adolescentes sem estes documentos era ainda maior .

Quanto à situação escolar, os dados comprovaram o flagrante afastamento do ambiente escolar $(72,6 \%$ não estavam estudando no momento da internação) e o preocupante índice de analfabetismo apresentado pelos internos
(108 adolescentes no total), como se pode observar na Figura 3.

Este quadro comprova a remota possibilidade de inserção destes jovens no mercado de trabalho, sendo relegados a atividades de subemprego. Este dado dramático e esclarecedor sobre a vida desses adolescentes, evidenciou a realidade vivenciada por todos que trabalham com adolescentes em situação de risco.

A situação de maior discriminação da mulher é evidenciada, ao constatar que apenas $17 \%$ das infratoras no ESD estavam estudando no momento da pesquisa, enquanto no IPS esse percentual era de $28 \%$ e na EJLA de $26 \%$.

Figura 2

Distribuição da população por idade. IPS, EJLA, ESD, 1994.

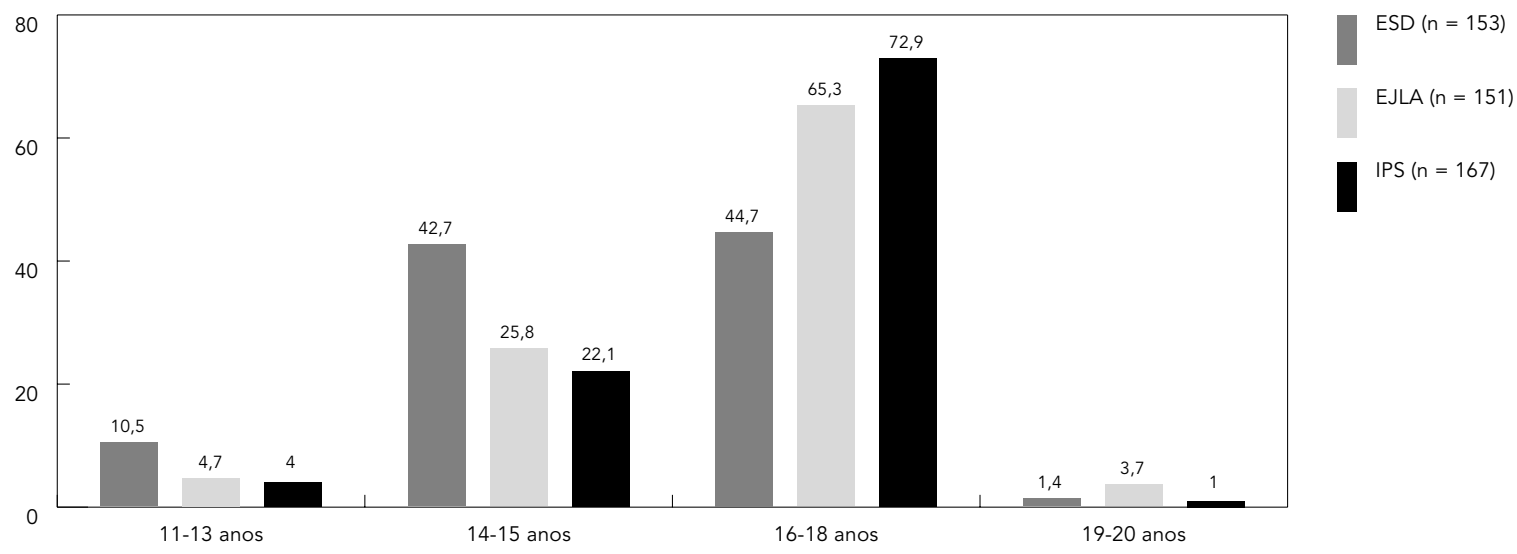

Figura 3

Distribuição dos adolescentes segundo educação formal. IPS, EJLA, ESD, 1994.

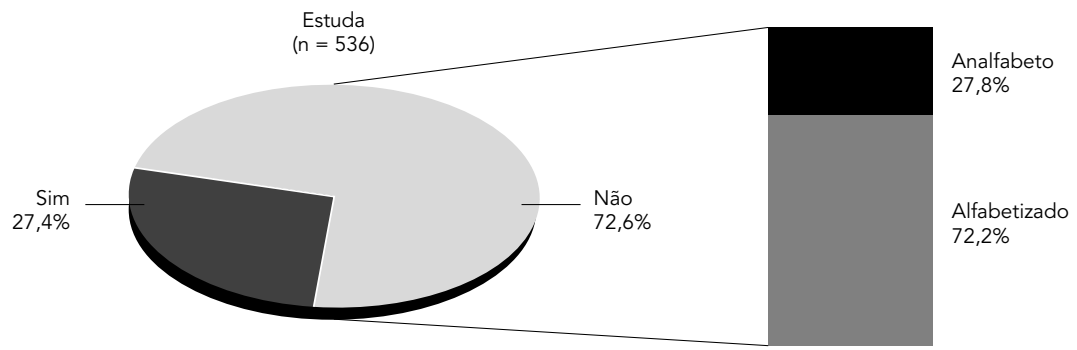


Também o analfabetismo alcançou maior freqüência entre as mulheres $(23 \%$ versus $20 \%$ no IPS e $18 \%$ na EJLA).

É interessante destacar que apenas $9 \%$ dos adolescentes foram além da sexta série. A ampla maioria dos que ainda estavam estudando antes da internação encontrava-se entre a primeira e quarta séries, reforçando a baixa escolaridade desta população.

No que se refere à situação do trabalho ficou evidenciado que até o momento da internação, $31 \%$ dos internos desenvolviam atividades de lavar e tomar conta de carro, manicure, vender picolé e outras atividades ambulantes, caracterizando o subemprego desta população. Mais uma vez encontrou-se uma situação diferenciada para a mulher: na ESD cerca de $14 \%$ já tinham trabalhado, enquanto nas escolas masculinas esse percentual foi bastante superior (35,6\% na EJLA e $42,7 \%$ no IPS).

A situação familiar dos internos mostrou que poucos adolescentes viviam em um lar composto de pai e mãe, conforme se pode constatar na Figura 4 (29,2\%). A mãe como chefe de família pode ser constatada em $25 \%$ dos lares dos entrevistados. A rua tornou-se uma alternativa de vida para $12,1 \%$ dos entrevistados.

A grande maioria dos internos revelou que seus pais são separados (71\%), porém vivos $(66,3 \%)$. Dezesseis por cento dos entrevistados nunca conheceram ou tiveram contato com o pai.

Muitos adolescentes já tinham filhos (cerca de $18 \%$ ) e apresentavam sua própria família.
Considera-se este índice elevado, levando-se em conta a precocidade com que ocorre. Alguns adolescentes tiveram filhos com apenas quatorze anos. Dentre os que não tinham filhos no momento da entrevista, houve diversos casos de gravidez em curso de meninas internadas ou de namoradas dos infratores. Dentre os jovens que já eram pais/mães, cerca de $15 \%$ tinham mais de um filho. A maioria desses jovens pais/mães não assumiram responsabilidade direta na criação do filho, deixando, em geral, essa tarefa a cargo de familiares de um dos genitores.

O distanciamento do adolescente de sua família foi constatado no fato de que $51 \%$ não recebiam visita alguma. Isto demonstra o quanto a ausência familiar pesa na história de institucionalização do jovem, caminho de cronificação de sua vida infracional e da qual os pais vão nitidamente se afastando (ou mesmo já estavam afastados).

No que tange à religião, 45,2\% dos adolescentes internados referem não a ter, enquanto $24,7 \%$ se autodenominam católicos, $19,5 \%$ evangélicos e 7,2\% espíritas (aí incluídas as religiões de origem africana: umbanda, candomblé etc.). Mas, apesar de quase a metade dos jovens relatar afastamento em relação à religião, suas famílias se mostram bem mais interessadas neste tema. Apenas $19 \%$ das famílias não têm religião, conforme informação dos entrevistados. A principal tendência religiosa presente nestas famílias é a evangélica (31,3\%), seguida pela católica $(27,5 \%)$.

Figura 4

Distribuição da população segundo situação familiar. IPS, EJLA, ESD, 1994.

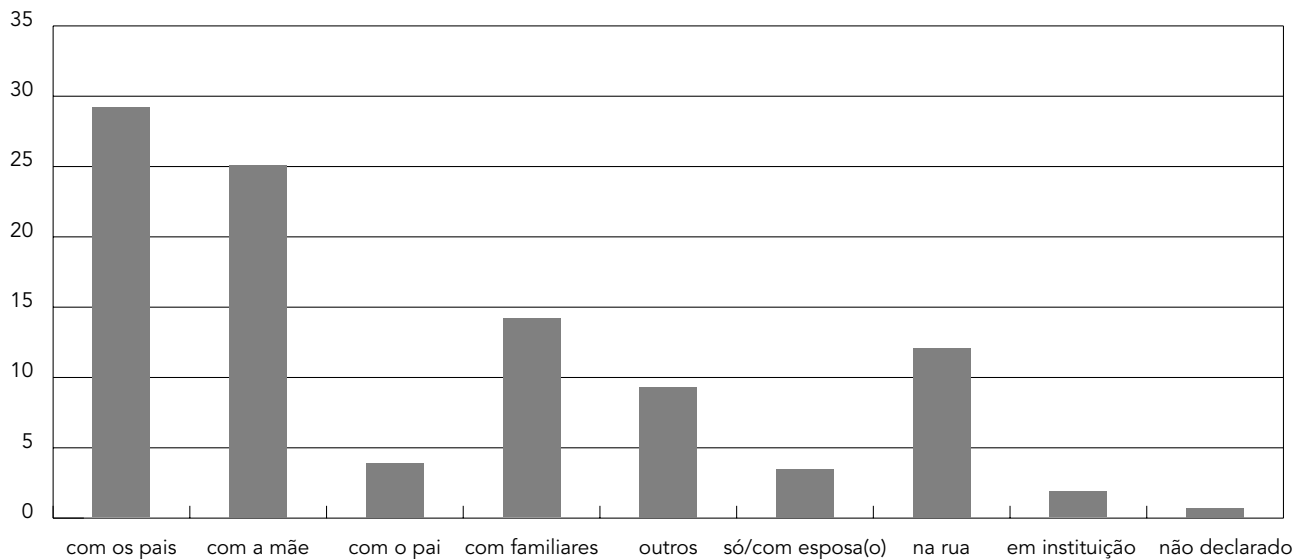


O principal problema imediatamente constatado durante a permanência dos pesquisadores na instituição foi a precariedade dos recursos humanos. Esta situação se agravou ainda mais a partir da promulgação da nova Constituição Federal de 1988, em que a liberdade de contratação de pessoal e de realização de concursos públicos havia sido cerceada. Além do mais, os Estados e Municípios foram convocados a assumir as instituições responsáveis pelo atendimento direto à população. Com essa visão descentralizadora proporcionada pela nova carta constitucional, os organismos federais se centraram no papel normatizador, deixando a execução dos atendimentos a cargo das unidades federadas. A exemplo do que ocorreu na área da saúde, isto se configurou um impasse, pois os atendimentos eram maciçamente promovidos por instituições com gerência federal.

Buscando-se solucionar este impasse, firmou-se um convênio entre o Estado do Rio de Janeiro e o Governo Federal, pelo qual o Estado iria gradativamente assumir seu papel executor. De início isto gerou insatisfações. Ante a passagem do atendimento para o Estado, os profissionais criaram uma questão trabalhista de modo a defender e garantir a condição de funcionários federais. Face a essa instabilidade, começaram a surgir muitos pedidos de aposentadoria e o número de licenças médicas aumentou, à medida que reduzia o número destes funcionários na ativa. Este fato agravou ainda mais a precariedade de recursos humanos nas instituições estudadas.

A qualidade do atendimento prestado aos infratores foi reduzindo paulatinamente. Muitas oficinas ficaram paralisadas, pois os instrutores se aposentaram e não havia possibilidade de renovação de pessoal. A pequena equipe de monitores inviabilizava todo o trabalho estruturado pelas demais equipes. Por vezes, os adolescentes permaneciam todos num pátio fechado, a fim de que o controle sobre seus comportamentos fosse absoluto, já que efetuado pela reduzida quantidade de monitores.

O ano de 1994 caracterizou-se, portanto, por um momento de decadência da capacidade produtiva das três instituições, que se deparavam com a necessidade de cumprir eficientemente três tarefas: manter a relação da equipe técnica com os juizados do Estado, informando-os sistematicamente sobre a permanência do interno; garantir a custódia e a segurança interna, pois respondem judicialmente pela custódia em caso de fuga; e manter em funcio- namento um projeto educacional voltado para as necessidades dos internos.

Esta situação particular provocava uma oscilação no objeto da atenção: ora o objeto era o relatório que devia ser entregue em prazo determinado e exíguo, ora o objeto era a árdua tarefa de controlar os conflitos, conter os desafetos e não permitir a evasão; ora o objeto era a confecção e sustentação de um projeto educativo.

Observou-se, então, que as reduzidas equipes técnicas restringiam o contato com adolescentes à tarefa de organizar o estudo de caso exigido pelos juízes. A pressão dos prazos judiciais acabavam inviabilizando um trabalho voltado para atender às exigências sócio-educativas da clientela. A equipe realizava uma avaliação do aluno fria e sem conteúdo, porque baseada em entrevista de gabinete, na qual o adolescente, numa absoluta falta de intimidade com aquele indivíduo que o inquiria, não revelava nada de substancial sobre si mesmo; e muitas vezes esta mesma situação se reproduzia com a família. Era notável o distanciamento aluno - assistente social. Essa dinâmica da equipe técnica contaminava todo o funcionamento das escolas, conforme podemos notar na entrevista feita com uma funcionária do setor pedagógico, que compara a situação presente com os compromissos do passado.

"Atualmente o que eu sinto é que a equipe técnica só pensa no desligamento do aluno. Não sei se isto se deve à cobrança dos juízes e as pessoas querem mostrar trabalho... Agora, o conteúdo do trabalho, como o funcionário trabalha com o menor..."

Ficou evidente a ausência de um projeto de cunho educacional em torno do qual os diferentes setores pudessem atuar. Era impossível para as pequenas equipes dar cabo de tarefas tão exaustivas e conflitivas entre si.

Foram inúmeras as dificuldades existentes na relação dos internos com os técnicos. Os monitores e técnicos eram os elementos mais importantes na convivência direta com o adolescente, porque muitas vezes conquistavam a sua confiança e preservavam laços de afetividade. Às vezes se transformavam em referência modelar com a qual o jovem se identificava. Muitos monitores e técnicos falaram da afetividade positiva estabelecida com jovens que se tornavam velhos conhecidos pelas repetidas entradas, por meio das quais o apego se atualizava, como se pode notar na fala de um técnico:

“...Um adolescente que tinha 12 anos, eu o conheci numa delegacia. Nós conseguimos tirálo de lá e trouxemos para o IPS, eu criei um laço muito forte com ele, porque era analfabeto; co- 
locamos ele para estudar e eu ficava às vezes até dez horas da noite tomando a lição dele... E ele me chamava de pai... Após oito meses ele foi desligado, e ele era muito agarrado comigo... Passaram-se cinco anos, estive lá no IPS, e ele estava lá, já com dezessete anos, mas quando me viu, ele se levantou e falou:-Aquele é meu pai. Veio e me abraçou, um abraço gostoso, $e$ conversamos... Ele é um garoto que falta nele uma atenção maior... Eu sempre procurei incutir nele o sentido de família: o pai dele era motorista de ônibus, mas era alcoólatra, agressivo, batia na mãe, nos filhos, era muito inconstante. Eu sinto que o garoto tem uma afinidade comigo... acho que foi a forma que ele tinha comigo particularmente, de ter uma pessoa, um vínculo afetivo com alguém... um homem, que pudesse substituir o pai dele..."

Muitas outras vezes, a relação entre técnicos e internos não se dava de forma tão amistosa. A provisoriedade da internação é considerada como um fator que dificulta o estabelecimento da relação entre o técnico e o interno. São funcionários que não se estimulam a investir num adolescente que logo irá embora ou internos que não se comprometem com absolutamente nada (até porque desacreditam do sistema), e apenas têm o objetivo de sair ou fugir, mesmo sabendo da absoluta falta de oportunidades e das dificuldades da vida na rua.

A relação dos monitores com os internos era permeada por comportamentos extremos: era dura, autoritária, com castigos (inclusive físicos), mas também estabelecia algum grau de confiança ("conversa de homem para homem...”). Esses funcionários mantinham um impressionante controle do coletivo, o que fazia crescer o respeito que o jovem tinha pelo monitor. Essa identidade propiciava o desenvolvimento de uma intimidade no contato pessoal e um aparente respeito no conjunto. Essa liderança se associava ao crédito de confiança que muitos monitores conquistavam.

O ano de 1994 caracterizou-se por ser um ano de crise no atendimento, com a ocorrência de rebeliões, pouco comuns a despeito dos muitos anos de privação e decadência que essas escolas enfrentaram. Em outubro de 1994 iniciou-se uma era de freqüentes rebeliões nestas instituições. Neste mês, ocorreram severas rebeliões nas duas instituições de custódia que atendem ao sexo masculino: IPS e EJLA. A instabilidade no atendimento que se implantou desde então, até hoje não está solucionada. As rebeliões de 1994 foram um marco, pois a partir de então, tornaram-se uma rotina na vida institucional. Estas rebeliões foram fruto da seguinte situação.
Havia um descrédito generalizado de que o convênio entre o governo Federal e Estadual não iria se implantar durante aquela gestão governamental. Entretanto, o firme empenho do Governador e o da Direção da FCBIA contradisseram esta visão dos agentes e técnicos. Esta situação gerava grande ansiedade que se espalhava por todos os níveis da instituição.

Com a entrada do Estado na gerência do atendimento surgiu a informação de que haveria uma renovação de pessoal no prazo de um ano. Durante o mês de agosto de 94, uma equipe de novos dirigentes permaneceram nas escolas para observar o funcionamento sem interferências e sem críticas ao trabalho que estava sendo realizado. No mês seguinte, os novos dirigentes assumiram definitivamente a direção das escolas, fato que levou a uma polarização: os funcionários estaduais representavam o novo, uma nova filosofia de trabalho, e os funcionários federais representavam o velho, a experiência que deveria ser respeitada, porém superada.

Os federais, os antigos, esforçavam-se por mostrar que eram capazes de dominar a situação, que, no entanto, já estava muito debilitada devido a estar há anos funcionando em condições precárias. Estes técnicos confiavam na liderança que possuíam para preservar a tranqüilidade na instituição. Os estaduais, os novos, veladamente criticavam o fato de os federais só se preocuparem com a segurança. Os novos se preocupavam com a qualidade do atendimento, com a dignidade e cidadania a ser oferecida, com métodos de aproximação voltados para acolher o jovem. Houve então uma incompatibilidade de métodos que se confrontaram, num conflito fadado ao insucesso: os federais detinham um inegável poder de liderança e uma linguagem afinada com a cultura do jovem. Os federais criticavam:

“...Perguntar o que eles querem comer, cobrir à noite com cobertor... Isto não vai dar certo, porque...o garoto não gosta de ser tratado dessa forma, ele gosta de ser tratado como adulto, ele é um marginal, quer ser respeitado como malandro...perguntar o que ele quer comer...vai ter que dar, e se não der o que prometeu vão enfrentar problemas..."

Por sua vez, os estaduais afirmavam:

“...Já percebemos algumas mudanças qualitativas no comportamento dos jovens; nossos métodos, por exemplo de ter mulheres como agentes comunitários (monitores) inclusive no período da noite foi inicialmente muito criticado, sofreu resistências, os antigos acharam absurdo ter mulheres trabalhando no pátio, entrar no dormitório à noite. Mas as mulheres se preo- 
cupam em observar se o adolescente está coberto, se ele estiver acordado pode conversar com ele. Isto impõe respeito..."

À medida que os estaduais foram chegando, os federais foram saindo das instituições. Os novos funcionários começaram, então, a perceber a dureza das condições de trabalho: instalações precárias, insistentemente precisando de reparos, as exigências imediatas dos juízes, as cobranças do Ministério Público, a pressão do número dos relatórios a serem apresentados, os prazos das audiências, a necessidade de manter vigilância quanto a fugas, as cobranças da sociedade. O cotidiano pressionava, impedindo a elaboração de um novo planejamento dentro da nova filosofia estabelecida no ECA, pensada para funcionar em unidades chamadas Centros de Atendimentos Integrados, que deveriam comportar no máximo cinqüenta adolescentes. A tentativa de adaptação do modelo à realidade institucional foi muito traumática.

A mudança de orientação e a insegurança reinantes foram logo percebidas pelos internos, que se comportavam com desconfiança, buscando conquistar o que queriam por intermédio da força ou do grito. Devido a isto, a transição gradual, tentada pelos funcionários estaduais, gerou ansiedade também para os internos, possuidores de uma cultura rígida na qual apenas existem dois lados: sangue bom (aquele que está do meu lado) e alemão (o inimigo contra quem devo lutar); conhecedores de um mundo onde batalham apenas para sobreviver. Nestas circunstâncias as relações foram se deteriorando. Os alunos iniciaram uma série de fugas e chegaram a exageros nas suas cobranças. Iniciaram-se então revoltas e violências incontidas de ambos os lados. Os adolescentes mais revoltados expunham suas escoriações. Todavia, as aparências foram mantidas. Apenas pela mídia foram conhecidos os instrumentos de castigo utilizados e os esconderijos onde eles eram secretamente guardados.

Coube portanto aos adolescentes institucionalizados a decisão para por um basta na insuportável indefinição de regras. Era preciso esclarecer e explicitar os caminhos, certamente pelo uso da força. Venceram os adolescentes, que fugiram, que destruíram boa parte das instituições e que apenas foram contidos por batalhões policiais. Conseguiram definir o que o governo e a competência técnica não foram capazes: saíram os funcionários federais e os jornais noticiavam que o Estado iria construir os Centros de Atendimentos Integrados, descentralizando o atendimento, proposta original, que parecia que iria ser assumida pelo Estado.

\section{A diferente realidade na instituição feminina}

A partir de 1994, o Educandário Santos Dumont se restringia a executar o cumprimento da medida judicial sócio-educativa de internação para jovens do sexo feminino, na faixa de 12 a 18 anos. A instituição tinha ainda a incumbência de promover a recepção e triagem das jovens, procedimento que antecede a representação do juiz.

Ao Educandário cabia proporcionar educação sistemática com curso regular e iniciação profissional; propiciar atividade sócio-recreativas que contribuam para o desenvolvimento da adolescente; orientar as famílias de adolescentes sob sua responsabilidade; orientar e encaminhar familiares e/ou responsáveis à utilização dos recursos necessários; mobilizar a comunidade visando a sua participação no processo de promoção social das adolescentes.

Observou-se que o Educandário viveu mudanças importantes nos seus procedimentos dos anos de 1994 e 1995. Houve melhorias materiais, como a reforma da piscina e do ginásio; assim como melhorias no trato com as adolescentes, como a reativação do salão de beleza e a transferência de muitos funcionários antigos que mantinham práticas viciadas e cronificadas.

Porém, foi a escola que menos mudanças apresentou durante todo o período em que se desenvolveu esta pesquisa, desmitificando uma imagem comum entre os técnicos de que as adolescentes infratoras representavam uma grande ameaça real. Foi a única instituição a manter uma mesma direção, que conseguiu se sustentar apesar de toda a crise vivida na passagem da responsabilidade do atendimento da FCBIA para o DEGASE. Ao contrário das outras duas escolas, o ESD não precisou acionar a força policial para manter a estabilidade interna. A única tentativa de insurgência foi debelada e controlada internamente.

Não obstante, existem aspectos de nossa vivência no Educandário que incitam pensar o feminino quando submetido neste lugar de controle.

O ESD era a escola pobre do complexo da Ilha do Governador, sempre a solicitar auxílio às suas vizinhas. Sua imagem era também muito negativa no interior do Sistema, o que ajudava a encerrá-la ainda mais num grande isolamento. Ninguém sabia muito bem informar o que acontecia na sua rotina e todos temiam uma maior aproximação.

A fama do Educandário assustava. Havia uma idéia de permanente conflito entre a administração da escola e a justiça. A vigilância e 
a segurança efetuadas pelos agentes educacionais se davam ostensivamente com pedaços de pau, para melhor desempenho de suas funções. Os funcionários das outras escolas consideravam o ESD como o local mais difícil para trabalhar, devido à natureza e ao comportamento indomável que as adolescentes apresentavam. O chefe de disciplina da EJLA explica:

"Elas são piores do que os meninos, e não há como ter controle quando todas começam a gritar ao mesmo tempo. Confunde quem é responsável pela disciplina, parece que a situação é mais grave do que na verdade é."

A situação de violência era explícita nesta instituição. A cena do pátio era degradante. A maioria estirada no chão, com absoluta indiferença se é ou não olhada, como se seres quase invisíveis, estampam o horror da indignidade que não escondem e não temem. Indiferença ante os pedidos sôfregos/sofridos dos novos agentes educacionais que tentam entender a jovem, o ambiente e o seu dever de controlar aquelas vidas sem mistério. "São vagabundas; não querem nada."

Os espancamentos eram comuns e justificados pela insubordinação inadmissível. "Se deixar elas tomam conta, ninguém controla. Elas é que vão bater na gente."; ou então, “O propósito é incutir limites. Educar é disciplinar para incutir limites."

O ESD incorpora muito da estranheza dessa jovem mulher interna. Ela não é socializável como o rapaz que, malgrado seu destino, preserva uma suposta dignidade - uma imagem menos selvagem. A adolescente infratora continua ali, ameaçadora, a desafiar o controle. A indiferença encobre dores não dizíveis; transparente desilusão. Presa na sua indiferença, a adolescente se debate quase indefesa. Há que ser forte. Se não há lugar para o temor, há que ser temível.

\section{Considerações finais}

"A lei se reforma, vem retomar um lugar ao lado do crime que a violara. O malfeitor, em compensação, é separado da sociedade. Deixa-a (...) numa cerimônia de luto. A sociedade que recuperou suas leis perdeu o cidadão que a violara" (Foucault, 1987:99).

O ano de 1994 será sempre lembrado como um marco histórico para o atendimento à infância e à adolescência no Estado do Rio de Janeiro. A passagem para a esfera estadual, há tanto tempo aguardada, mostrou-se muito conflituada e seus reflexos ainda estão presentes, nas sucessivas rebeliões que vêm ocorrendo desde então. O ano de 1997 teve um saldo de 273 fugas e 10 mortes decorrentes das rebeliões do IPS e EJLA (Assis, 1999).

Constata-se, às portas do século XXI, a perpetuação do descaso para com os jovens infratores. O governo estadual continua sem encarar como prioridade o atendimento aos jovens nas instituições de custódia: os Centros de Atendimentos Integrados demoraram muitos anos para começar a funcionar; algumas instituições ainda se apresentam deterioradas quanto à estrutura física e escassez de material; não se implementou a escola formal nem iniciação profissional efetiva; houve inúmeras trocas de chefia e juízes foram afastados. Continuam, pois, superlotadas, inapropriadas para a socialização dos jovens, desumanas e descumprindo o ECA. Em 1998 a EJLA foi totalmente destruída pelas rebeliões e os jovens foram mandados para o presídio Muniz Sodré onde predominam condições reconhecidamente desumanas de habitação, higiene e superlotação, sendo comparado a campos de concentração (Assis, 1999).

A ineficiência das políticas públicas praticadas no país há mais de um século refletiu-se claramente nos dados apresentados neste artigo. A exclusão e a desigualdade social ficaram flagrantes em toda a vida destes jovens. Estes provêm de famílias pobres que habitam nas áreas mais carentes da cidade. Muitos dos jovens vivem em comunidades com freqüentes episódios de violência, geralmente oriundos de conflitos entre o tráfico de drogas e a polícia. A cultura do crime e da rua está presente na facilidade do acesso a armas e a galeras ou bandos violentos, como demonstra Zaluar (1994:9):

"Seus heróis são outros. Na falta de um movimento operário forte de onde saiam líderes trabalhadores com fama, eles se voltam para os eternos valentes da nossa cultura popular que desafiam, passam rasteira e se negam a esse mundo do trabalho. Se antes, por lá, os valentes eram os simpáticos malandros, hoje são os perigosos e armados bandidos. A navalha foi substituída pelo "oitão" ou minimetralhadora, o leal corpo a corpo pela tocaia traiçoeira, a lei do mais valente pela lei do mais armado".

Outros autores, como Cruz-Neto \& Minayo (1994:207), comentam sobre o processo de extermínio na sociedade brasileira. Mostram como os pobres são as principais vítimas deste processo, porque fazem parte de um processo de aniquilamento, de exclusão e de eliminação de grupos sócio-econômicos e culturais considerados "marginais", supérfluos" e "perigosos":

"vai se construindo no país um senso comum de que temos um excesso de população 
(pobre), economicamente supérflua e socialmente sem raízes, candidata à delinqüência e, portanto, sem utilidade numa sociedade competitiva que aspira às riquezas da civilização $e$ à modernidade".

Tais jovens pobres são, por vezes, também agentes deste extermínio, à medida que são recrutados desde pequenos, acostumando-se a usar armas e drogas, convivendo com pessoas "sem preocupações com a lei e a moral, sobretudo relativizando o sentido da vida e banalizando a morte" (Cruz-Neto \& Minayo, 1994:211). Passam a ser os executores últimos de sua própria gente.

Pode-se ainda perceber que a vivência na instituição configura-se como uma etapa de aprendizado do crime, e jamais como uma etapa de ressocialização. O sentimento de impotência vivida pelos profissionais destas instituições, a histórica precariedade de recursos humanos e materiais e a prática institucional impregnada pelo desrespeito, também comprovam a insanidade do sistema e das políticas públicas. Por seu lado, a sociedade continua solicitando medidas de repressão e se omitindo na luta pela melhoria da qualidade do atendimento público oferecido a estes jovens.

A maior prova da ineficiência do sistema é o destino dos jovens ao sair da instituição. São postos na rua da mesma maneira que entraram, desamparados, sem documentos, sem escolaridade e sem chances de se profissionalização. São jovens estigmatizados. Aqueles que possuem familiares que podem dar suporte emocional e financeiro têm mais chance, se comparados aos que provêm de famílias com menos condições para tal. O meio comunitário, com muita freqüência, contribui reforçando a utilização de drogas e o convívio com traficantes. $\mathrm{O}$ círculo vicioso se fecha para alguns jovens, contribuindo para a reincidência no ato infracional.

Pode-se constatar que a sociedade ainda não consolidou uma rede de atendimentos básicos, capaz de sobreviver às mudanças que se processam no plano político-administrativo, de modo a viabilizar uma retaguarda sócioeducativa, primeiro passo a ser dado para a implantação efetiva do Estatuto da Criança e do Adolescente.

Nove anos após a promulgação da lei, muitas críticas têm surgido acerca das medidas legais propostas pelo ECA, num momento em que a criminalidade é generalizada nos centros urbanos, havendo um recrutamento maior de crianças e adolescentes envolvidos nestas atividades. Os meios de comunicação de massa disseminam os vários tipos de atos infracionais cometidos e magnificam a intensidade dos crimes mais violentos. Há, na população, profundo impacto causado pelos atos infracionais graves cometidos por adolescentes, que têm provocado na sociedade uma crescente reação de antagonismo para com os jovens infratores.

Surge daí a preocupação crescente da sociedade com a responsabilidade penal e a proposta de modificação da idade de imputabilidade jurídica, respaldado no fato de que cerca de $65 \%$ dos internos destas instituições têm 16 anos ou mais.

Não é necessário se alongar mais sobre o flagelo que estas escolas de internação têm passado e impõem sobre a vida de milhares de jovens. A falência do sistema e a grotesca negligência das autoridades são um fato facilmente constatada pela população em geral. A saída para a crise que acomete as escolas de internação continua a ser a atenção descentralizada, com melhor qualidade do ensino ministrado, equiparado com ensino profissionalizante sério e atual, para que o adolescente não chegue ao mercado completamente defasado. É preciso reafirmar que as escolas precisam se munir com um aparato pedagógico sério. Não se pode continuar a colocar o adolescente preso num paredão alto, amontoado com outros, tal qual vem cronicamente se sucedendo no país.

É também necessário rever os prazos de internação, adequando-os ao prazo mínimo, a fim de que se possa montar um trabalho educativo em nível de instrução e de profissionalização que possa realmente surtir efeito. Os prazos de internação praticados em 1994 não ultrapassavam em média os três meses; o ensino formal e as oficinas profissionalizantes ainda são intermitentes e ineficientes. Cabe relembrar que a privação de liberdade deve ser aplicada somente em casos extremos, pois existem outros dispositivos menos danosos, que podem ser muito mais eficientes em casos menos graves (liberdade assistida, prestação de serviço à comunidade, semi-liberdade), tendo como mira a filosofia que permeia as medidas sócio-educativas. No entanto, se a internação deve ser restrita aos casos extremos, sua aplicação também deve ser rigorosa, não apenas quanto ao tempo, mas principalmente em relação à qualidade da assistência prestada. A grande rotatividade de internos traz conseqüências severas. Em primeiro lugar, exige que a equipe técnica das escolas efetuem avaliações muito rápidas, para suprir os prazos exíguos das audiências realizadas pela justiça. Desta forma, a relação estabelecida entre o técnico e o interno fica seriamente prejudicada. Em segundo lugar, gera um clima de ansiedade no jovem, que 
impede a eclosão de qualquer movimento em direção à mudança na sua situação subjetiva.

É premente que se ampliem as atividades dos Centros de Atendimentos Integrados, para que se possa oferecer atendimento a grupos menores de adolescentes, providência que certamente facilitaria a própria segurança e ressocialização dos adolescentes infratores. É preciso, portanto, encarar o problema mais por uma ótica técnica e menos como um voluntarismo assistencialista, praticado por muitos profissionais, artistas, religiosos e outros grupos.

Outra forma de atuar sobre o problema dos jovens infratores na sociedade é por meio da ênfase nos trabalhos comunitários. O resultado positivo dessas experiências que priorizam a intervenção primária deve ser levado em conta no momento de elaboração de políticas de atendimento.

Um exemplo digno de nota é o programa desenvolvido na Mangueira, patrocinado pela iniciativa privada e pela própria comunidade. Este trabalho abrange uma larga faixa etária, da creche à adolescência, mantendo em pleno funcionamento atividades pedagógicas, artísti-

\section{Referências}

ALTOÉ, S., 1990. Infâncias Perdidas. O Cotidiano dos Internatos-Prisão. Rio de Janeiro: Xenon.

AMADO, J., 1984. Capitães de Areia. São Paulo: Círculo do Livro.

AQUINO, W., 1997. Tráfico na Mangueira 'importa' crianças. Jornal do Brasil, Rio de Janeiro, 13 abr. 1997. p. 34.

ASSIS, S. G., 1999. Traçando Caminhos em Uma Sociedade Violenta. A Vida de Jovens Infratores e seus Irmãos não Infratores. Rio de Janeiro: Editora Fiocruz.

BASTOS, M., 1994a. As Implicações Psíquicas Presentes no Ato Infracional de Repetição. Divisão Educacional Padre Severino. Relatório parcial de pesquisa. Rio de Janeiro: (mimeo.)

BASTOS, M., 1994b. As Implicações Psíquicas Presentes no Ato Infracional de Repetição. Escola João Luiz Alves. Relatório parcial de pesquisa. Rio de Janeiro: (mimeo.)

BASTOS, M., 1995. As Implicações Psíquicas Presentes no Ato Infracional de Repetição. Educandário Santos Dumont. Relatório parcial de pesquisa. Rio de Janeiro: (mimeo.)

CRUZ-NETO, O. \& MINAYO, M. C. S., 1994. Extermínio, violentação e banalização da vida. Cadernos de Saúde Pública, 10 (Sup.1):199-212.

FALEIROS, V. P., 1995. Infância e processo político no Brasil. In: A Arte de Governar Crianças (F. Pilotti \& I. Rizzini, org.), pp. 47-98, Rio de Janeiro: Instituto Interamericano del Niño/Editora Universitária Santa Úrsula/Amais Livraria e Editora. cas e esportivas da maior qualidade. A produtividade dessa iniciativa fica expressa na fala do Juiz responsável pelo atendimento ao adolescente infrator sobre "o ínfimo número de jovens da Mangueira que dão entrada no circuito judicial" (Aquino, 1997). Quando a própria comunidade se organiza ou é convidada a participar ativamente de um trabalho sério e criativo, os resultados são praticamente imediatos. Isto comprova que a parceria entre os equipamentos do Estado e da sociedade civil, aliada ao envolvimento com a comunidade, é uma medida de absoluta necessidade na atuação.

Cumpre ainda lembrar que a complexidade da experiência e do fenômeno da violência exige a ultrapassagem de simplificações e a abertura de pontos de vista que integrem atuações oriundas de várias disciplinas, setores, instituições e comunidades. É fundamental despertar o interesse das autoridades e da sociedade para a necessidade de priorizar ações para a infância e adolescência, visando à real modificação da sociedade. É crucial investir social e politicamente para trazer de volta à sociedade, com dignidade, os jovens infratores.
FOUCAULT, M., 1987. Vigiar e Punir. História da Violência nas Prisões. Petrópolis: Vozes.

FUNABEM (Fundação Nacional de Bem-Estar do Menor), 1984. FUNABEM. Ano 20. Rio de Janeiro: FUNABEM

HAWKINS, J. D., 1996. Delinquency and Crime. Cambridge: Cambridge University Press.

LONDOÑO, F. T., 1991. A origem do conceito menor. In: História da Criança no Brasil (M. Del Priori, org.), pp. 98-111, São Paulo: Contexto.

LUPPI, A. C., 1987. Malditos Frutos do Nosso Ventre. São Paulo: Ícone.

MONES, P., 1992. When a Child Kills. New York: Pocket Books.

MS (Ministério da Saúde), 1991. Estatuto da Criança e do Adolescente. Brasília: Ministério da Saúde.

OLIVEIRA, M. B., 1998. Os Porões da Pólis. In: A Pesquisa nas Ciências do Sujeito. (L. Dupret, org.), pp. 107-129, Rio de Janeiro: Revinter.

RIZZINI, I., 1993. Assistência à Infância no Brasil: Uma Análise de Sua Construção. Rio de Janeiro: Editora Universitária Santa Úrsula.

SHOEMAKER, D. J., 1996. Theories of Delinquency. An Examination of Explanations of Delinquent Behavior. New York: Oxford University Press.

ZALUAR, A., 1994. Condomínio do Diabo. Rio de Janeiro: Editora Revan. 